\title{
Qualidade de Experiência do Usuário em uma Rede WiFi Municipal usando Streaming de Vídeo
}

\author{
Juliano Ratusznei, Waleska Zanotto, Carlos Kamienski \\ Universidade Federal do ABC (UFABC) \\ \{juliano.r, cak\}@ufabc.edu.br, waleskacomk@gmail.com
}

\begin{abstract}
Resumo. Redes WiFi Municipais tem o objetivo de oferecer acesso gratuito à Internet através de rede sem fio, para incentivar a participação do cidadão $e$ promover a inclusão digital. No entanto, essas infraestruturas em geral não possuem desempenho satisfatório, além de não estarem disponíveis resultados de avaliação de desempenho. A abordagem desse artigo é a realização de experimentos envolvendo a utilização de streaming de vídeo em praças digitais distribuídas pelas diversas regiões da cidade de São Paulo. Foi realizada uma análise de desempenho nas praças utilizando-se de métricas que avaliam tanto a Qualidade de Experiência do usuário, como a Qualidade de Serviço da rede. Os resultados mostram que para diferentes praças, dias e níveis de qualidades de vídeo, na maioria das vezes o resultado é satisfatório para os usuários.
\end{abstract}

\begin{abstract}
Municipal WiFi Networks aim at providing free Internet via wireless network infrastructures, for promoting citizen participation and bridging the digital divide. However, such infrastructures frequently suffer from poor performance, which is worsened by a general lack of results obtained in performance analysis studies. The approach of this paper is the use of video streaming in the so-called digital squares with free WiFi access, distributed throughout five regions of São Paulo City. A performance analysis study was conducted in squares using metrics such as Quality of Experience of users and Quality of Service of the network. Results show that for different squares, days and video qualities, in most cases the experience is satisfactory for users.
\end{abstract}

\section{Introdução}

Devido a atual popularidade dos dispositivos móveis e sua crescente utilização em locais públicos, a disponibilização de Internet tem se tornado um serviço cada vez mais importante ao redor do mundo. No início dos anos 2000 acreditava-se que as cidades teriam redes WiFi Municipais com ampla cobertura de sinal para promover o acesso a Internet à população e a inclusão digital e incentivar a criação de serviços rumo às cidades inteligentes [Bar \& Park 2006]. Principalmente nos Estados Unidos, onde a oferta de rede 3G chegou mais tarde, praticamente uma centena de cidades iniciaram projetos para oferecer WiFi gratuitamente à população, inclusive dentro de prédios residenciais. No final da década a maioria dos projetos já havia sido descontinuado ou então cancelado, devido a problemas regulatórios e técnicos, altos custos e eventualmente baixa demanda [Fraser 2010]. Atualmente existe um grande debate sobre as vantagens e desvantagens da redes WiFi Municipais [Potts 2014].

No entanto, várias iniciativas sobreviveram e inclusive muitas foram criadas a partir de 2010, justamente com foco em fornecer conectividade WiFi em espaços 
públicos, tanto abertos como praças e parques, como fechados como bibliotecas e órgãos públicos. Nesse contexto se insere o programa WiFi Livre SP ${ }^{1}$, iniciado em 2014 pela prefeitura de São Paulo para tornar a Internet mais acessível à população. O programa WiFi Livre SP implantou 120 praças digitais, onde o acesso é irrestrito e gratuito a qualquer cidadão. O programa foi projetado para oferecer $512 \mathrm{Kbps}$ por usuário, para download e upload além de certas garantias de atraso mínimo. O serviço é prestado por duas empresas selecionadas através de um processo de licitação. As área de cobertura englobam as 5 regiões da cidade de São Paulo: Centro, Zona Norte, Zona Sul, Zona Leste, Zona Oeste.

O programa WiFi Livre SP vem sendo sistematicamente monitorado para compreender o uso das praças, a sua disponibilidade e desempenho [Ratusznei 2015]. A mensuração do efeito da política pública de oferta de conexão à Internet gratuita através de uma rede WiFi Municipal envolve uma equipe com atuação interdisciplinar para realizar avaliação qualitativa e quantitativa da qualidade das praças digitais sob a percepção dos usuários. Foram realizadas avaliações qualitativas com pesquisa de campo sobre a opinião dos usuários, cuja apresentação, no entanto, está fora do escopo desse artigo. Com relação à avaliação quantitativa, foram realizados estudos de avaliação de desempenho para averiguar os níveis de Qualidade de Serviço (QoS) usando métricas de rede, assim como para averiguar a Qualidade de Experiência (QoE) percebida pelo usuário, através de experimentos com streaming de vídeo. A metodologia utilizada tem por objetivo revelar informações que poderão ser úteis para aprimorar a abordagem da implementação técnica que baliza o projeto e instalação e operação das praças digitais, visando estudar os efeitos da Internet, em suas múltiplas dimensões, na vida dos cidadãos e das comunidades atendidas pela política de oferta de conexão gratuita de conexão WiFi.

Dada a atual importância das aplicações de vídeo, o presente artigo apresenta a avaliação de desempenho de aplicações de streaming de vídeo praças digitais de São Paulo, além de compará-las com dados de desempenho de rede. Os resultados confirmam que as métricas de QoS e QoE estão intimamente relacionadas e comprovam disparidade entre as praças com relação à qualidade de visualização de vídeos. Algumas praças permitem a visualização com qualidade adequada de vídeos com taxa de codificação de até $1200 \mathrm{Kbps}$, enquanto que outras geram desconfortos aos usuários (número e tempo de interrupções do vídeo) que impedem uma experiência satisfatória com bom nível de qualidade.

Na sequência do artigo, a sessão 2 apresenta os conceitos básicos e os trabalhos relacionados. A Sessão 3 apresenta a metodologia que foi adotada para avaliar o desempenho das aplicações de streaming de vídeo. A sessão 4 e 5 apresentam, respectivamente, os resultados obtidos no trabalho e uma discussão sobre os resultados. Finalmente, a sessão 6 apresenta a conclusão do trabalho.

\section{Trabalhos Relacionados}

Várias cidades de grande porte e importância no Brasil e no mundo disponibilizam acesso a redes WiFi públicas em larga escala, como São Paulo. Em termos da quantidade de pontos de acessos, destacam-se Roma, Barcelona, Zaragoza, Caracas,

\footnotetext{
${ }^{1}$ http://wifilivre.sp.gov.br
} 
Adelaide, Xangai e Buenos Aires. No então, na maioria delas o acesso não é gratuito ou então o tempo de uso gratuito é limitado. Independente do tipo de acesso fornecido, não existem em geral resultados amplos de estudos que avaliam a qualidade da rede, de acordo com a percepção do usuário, como esse artigo se propõe a mostrar.

Existem várias referências na literatura sobre avaliação de WiFi e sobre avaliação de qualidade de vídeo, mas não foi encontrado nenhum resultado específico que contemple o uso de streaming de vídeo para compreender o funcionamento de um programa de WiFi público e gratuito. O trabalho desenvolvido por Sommers (2012) tem como objetivo entender o desempenho das redes móveis comparando o desempenho de redes celular e de WiFi utilizando de dados do Speedtest.net. O estudo considera o desempenho espaço-temporal (upload/download) da taxa de transferência e RTT. Mais de 3 milhões de testes foram realizados por usuários iOS e Android em 15 diferentes áreas metropolitanas. Um artigo correlato em termos de medida de larga escala em lugares de conexão sem fio aberta ao publico foi o trabalho de Ghosh [2011] que obteve métricas de locais diversos como restaurantes, bares, empresas e cafeterias em duas cidades dos EUA com o intuito de propor um modelo de utilização das redes públicas.

Um estudo de grande porte envolvendo dezenas de milhares de redes sem fio WiFi em dois períodos de uma semana em janeiro de 2014 e janeiro de 2015 concluiu que a demanda pelo uso de redes sem fio mantém um crescimento rápido, principalmente pelo aumento da quantidade de dispositivos conectados e uso de aplicações de vídeo como YouTube e Netflix [Biswas et. al 2015]. Embora as redes estejam localizadas em ambientes particulares (cafeterias, bares, etc.) e portanto distintos das redes WiFi Municipais, o estudo contribui para ressaltar a importância da oferta de serviços públicos que atendam adequadamente as necessidades dos cidadãos, principalmente pela predominância do uso de aplicações de vídeo streaming que consomem considerável quantidade de recursos de rede.

A predominância do acesso a vídeo por usuários redes sem fio em dispositivos móveis tem despertado a atenção para a necessidade de compreender a Qualidade de Experiência (QoE) com foco na percepção do usuário, em vez de usar o mapeamento de métricas de Qualidade de Serviço (QoS) de rede para QoE [Baik et. al 2015]. A medição de qualidade de vídeo tradicionalmente tem utilizado métricas que comparam o vídeo recebido com o vídeo transmitido, ou seja, o resultado da transmissão com a referência armazenada no servidor, como PSNR (Peak Signal to Noise Ratio) [SerralGracia 2010], SSIM (Structural Similarity) [Wang 2002] e VQM (Video Quality Metric) [Pinson 2004]. Essas métricas auxiliam o processo de compreensão da experiência do usuário, mas não capturam o possível sentimento do usuário com relação à qualidade do vídeo assistido e por isso estão sendo criadas novas métricas que avaliam QoE [Balachandran et. al 2013].

A percepção do usuário é afetada por diferentes fatores que podem ser mensurados de forma objetiva e subjetiva. A relação da qualidade com o buffer tende a apresentar impacto significativo na percepção do usuário, como o tempo de início do vídeo (playback start time), a quantidade de vezes que a imagem é congelada (number of interruptions), a duração dos congelamentos de imagem (duration of interruptions) e o local no vídeo onde ocorrem os congelamentos [Juluri 2016] [Baik et. al 2015].

Nesse trabalho foi feita a opção de avaliar a qualidade de vídeo sob a percepção do usuário, assumindo como premissa que a interrupção do vídeo causada pelos 
mecanismos de buferização é o fator que mais afeta negativamente a qualidade da experiência. Além desses fatores, a diminuição da taxa da codificação para vídeos adaptativos também afeta o usuário, mas nesse trabalho foram usados vídeos com codificação fixa, para possibilitar uma comparação justa entre praças, dias e horários.

\section{Metodologia}

Esse artigo se concentra em resultados de QoE com foco na percepção da qualidade de vídeo pelo usuário, uma vez que resultados de QoS com foco em desempenho de rede foram apresentados anteriormente em [Ratusznei 2015]. Apenas alguns resultados de QoS atualizados no período dos experimentos com vídeo são apresentados na seção 4.

\subsection{Ferramentas}

Existem ferramentas que mensuram métricas como PSNR e SSIM, como EvalVid [Klaue 2003], que no entanto não foram utilizadas pela escolha da técnica de percepção da qualidade baseadas nas interrupções do vídeo. Como nenhuma ferramenta foi encontrada que possibilitasse a medição das interrupções de vídeo, houve a necessidade de buscar soluções alternativas, que permitissem a coleta das métricas desejadas. A ferramenta encontrada que mais se aproxima da necessidade foi o $\mathrm{VLC}^{2}$, na versão 2.2.1, um reprodutor multimídia multiplataforma de código aberto que transmite vídeo via streaming em várias codificações e fornece bibliotecas para customizar aplicações cliente. O servidor de vídeo foi configurado para iniciar a transmissão sob comando do cliente e foi instalado na UFABC.

O cliente de vídeo é responsável por se conectar ao servidor e solicitar a transmissão do vídeo, além de iniciar simultaneamente a medição de atraso (RTT) e perda de pacotes na rede usando mensagens ICMP através do programa ping. A biblioteca do VLC permite identificar quando o vídeo sofre interrupção (congelamento) e quando a transmissão normal é iniciada ou restabelecida. Além disso, permite que o cliente obtenha dados sobre a taxa de transmissão que está sendo efetivamente recebida (vazão), para compará-la posteriormente com a taxa de codificação do vídeo.

\subsection{Procedimentos para Medição de QoS e QoE}

As medições de QoS foram realizadas com dados coletados das empresas prestadoras do serviço e das medições realizadas pelo SIMET Box [Ratusznei 2015]. Esse artigo se concentra na metodologia e resultados de experimentos de medição de QoE de vídeo em cinco praças localizadas em cinco regiões de São Paulo. Foram realizados experimentos com duas taxas de codificação de vídeo nas cinco praças em todos os dias da semana, durante novembro e dezembro de 2015. Cada experimento foi replicado 30 vezes e os intervalos de confiança ao nível de $99 \%$ foram computados. Cada trecho de vídeo possui 1 minuto de duração, de modo que com dois tipos de vídeo (de qualidades diferentes) com 30 replicações somente o tempo dos experimentos consome uma hora. Além disso, em média foram necessários 40 minutos para troca de vídeo, intervalos entre replicações e eventuais falhas de conexão.

A Tabela 1 traz as lista dos parâmetros fixos utilizados nos experimentos. Para garantir a justiça na avaliação, o usuário (sempre o mesmo, para garantir justiça nas

${ }^{2}$ http://www.videolan.org/vlc/ 
avaliações) posicionou-se à mesma distância (10 metros) do Access Point (AP) em todos os experimentos. O valor de 10 metros foi escolhido após observação empírica do comportamento típico dos usuários nas praças. Na maioria das vezes, os usuários não tem consciência da localização do AP e utilizam a conexão WiFi de qualquer ponto da praça. Não houve variação da distância devido à complexidade logística, condições climáticas e demanda de tempo físico para a realização de novos experimentos. O vídeo utilizado tem duração de 60 segundos e foi editado a partir de um vídeo com grande número de visualizações no YouTube ${ }^{3}$. A ideia é permitir replicações com duração de um minuto e ao mesmo tempo utilizar um vídeo que misture cenas escuras e claras e com pouco e muito movimento.

A Tabela 2 traz os fatores e níveis, ou seja, os parâmetros variados em experimentos diferentes e os valores que eles assumiram. Foram avaliadas cinco praças digitais, de acordo com a seção 3.3. Dois níveis de qualidade de vídeo foram avaliados, codificação com taxas de $1200 \mathrm{Kbps}$ e $840 \mathrm{Kbps}$, com o objetivo de complementar os dados de uso e desempenho das praças com vídeos acima de $512 \mathrm{Kbps}$, a taxa média projetada por usuário. Houve coletas em todos os dias da semana, variando de $7 \mathrm{~h}$ às 18h. Cada praça foi avaliada em todos os dias da semana em horários pré-estabelecidos. Novamente devido à complexidade logística da realização dos experimentos não foram realizados medições em todas as horas do dia em todas as praças em todos os dias da semana.

Tabela 1: Parâmetros

\begin{tabular}{|l|l|}
\hline Parâmetro & Valor \\
\hline Distância do AP & $\cong 10$ metros \\
\hline Servidor de destino & UFABC \\
\hline Duração & 60 segundos \\
\hline Captura & 1 segundo \\
\hline
\end{tabular}

Tabela 2: Fatores e Níveis

\begin{tabular}{|l|l|}
\hline Fator & Nível \\
\hline Praça & Centro, Norte, Sul, Leste, Oeste \\
\hline Qualidade & 1200 Kbps, 840 Kbps \\
\hline Hora & 7:00h às 18:00h \\
\hline Dia & Todos os dias da semana \\
\hline
\end{tabular}

\subsection{Seleção de Praças, Datas e Horários de Medição}

Foram selecionadas cinco praças entre as 120 do programa WiFi Livre SP, uma de cada região. A Tabela 3 apresenta as praças e o número máximo de usuários para o qual elas foram projetadas, e a Figura 1 apresenta a sua localização no mapa.

- Utilização da praça: baseada no número de usuários conectados por hora do dia nos últimos três meses antes da realização dos experimentos;

- Segurança da praça: como as medições são realizadas in loco, foi considerada a taxa de criminalidade;

- Acessibilidade e deslocamento: as cinco praças foram visitadas todos os dias de medição e portanto foi considerado a facilidade de deslocamento entre elas.

Tabela 3: Praças Selecionadas

\begin{tabular}{|c|c|c|c|c|c|}
\hline Região & Centro & Norte & Sul & Leste & Oeste \\
\hline Praça & $\begin{array}{c}\text { Biblioteca } \\
\text { Dom José } \\
\text { Gaspar }\end{array}$ & $\begin{array}{c}\text { Praça Nossa } \\
\text { Senhora dos } \\
\text { Prazeres }\end{array}$ & $\begin{array}{c}\text { Largo Dona } \\
\text { Ana Rosa }\end{array}$ & $\begin{array}{c}\text { Praça Silvio } \\
\text { Romero }\end{array}$ & $\begin{array}{c}\text { Praça Conde } \\
\text { Francisco } \\
\text { Matarazzo }\end{array}$ \\
\hline Usuários & 150 & 50 & 75 & 100 & 50 \\
\hline
\end{tabular}

${ }^{3}$ https://youtu.be/05I6WZg8v8c 


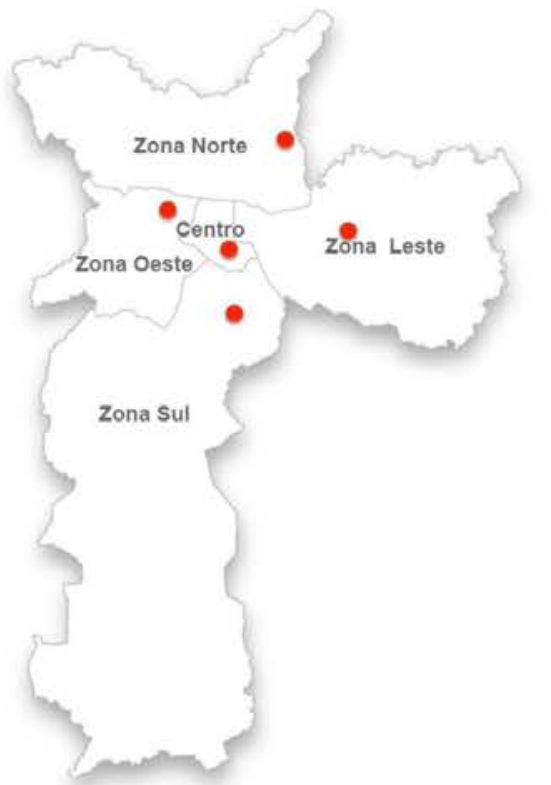

Figura 1: Distribuição das praças na cidade de São Paulo

A Figura 2 apresenta o número médio de usuários conectados nas cinco praças selecionados durante um período de três meses. Esse parâmetro pautou tanto a escolha dessas praças quanto a concepção do cronograma e horários de medição em cada praça. Dada a diferença de perfil de usuário e de utilização entre dias de semana e finais de semana, foram realizadas medições em todas as praças em todos os dias. Devido a limitações logísticas, não foi possível realizar medições em várias horas do dia em vários dias da semana em uma mesma praça. O cronograma foi integralmente cumprido em aproximadamente 16 dias.

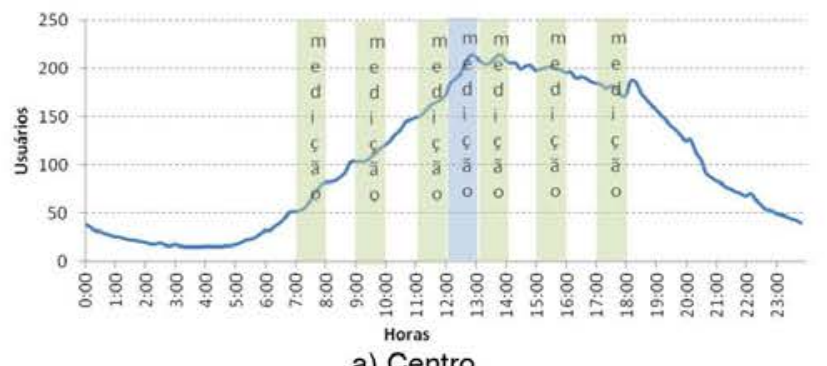

a) Centro

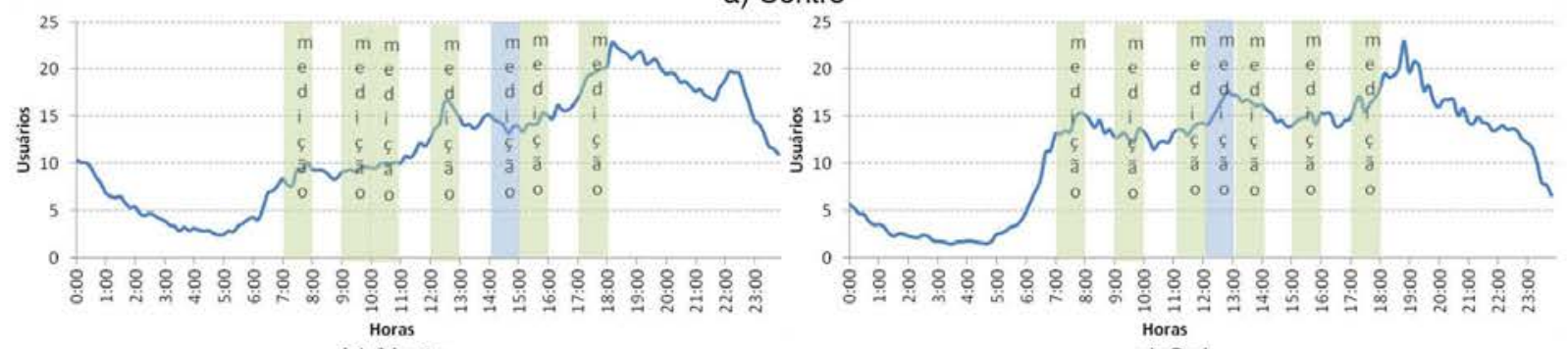

b) Norte

c) Sul
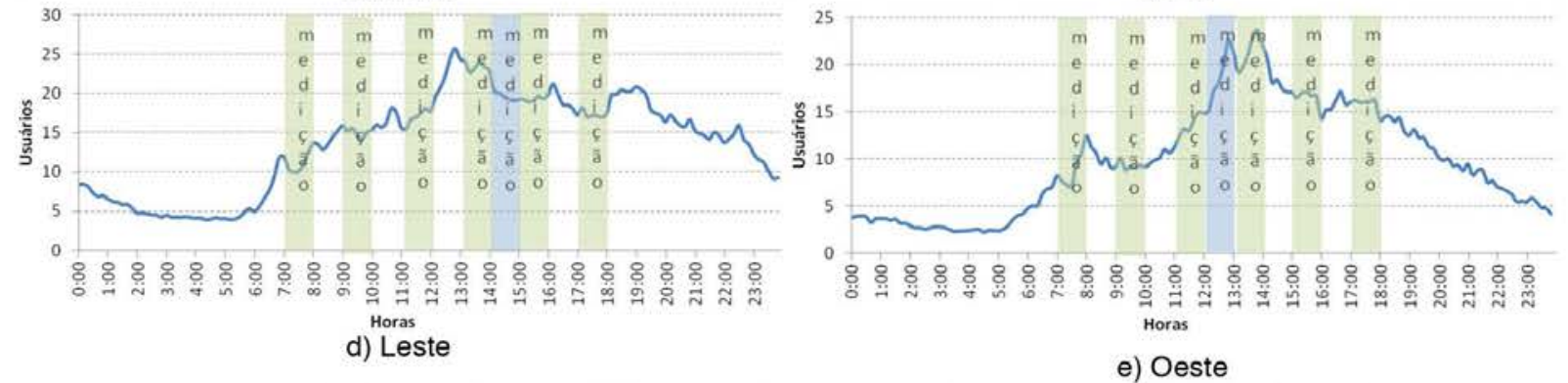

Figura 2: Número de usuários por horas do dia nas praças selecionadas 


\subsection{Métricas}

As métricas utilizadas para avaliar as praças são divididas em duas categorias: QoS do serviço WiFi na praça QoE do usuário com relação ao vídeo.

- QoS: obtidos através da execução do comando ping durante as medições e através da coleta de dados provenientes das empresas prestadores do serviço.

- Nível de utilização da praça: número de usuários que utilizam a praça dividido pelo número máximo de usuários previstos (Tabela 3). O número máximo determina a capacidade da rede WiFi da praça e do enlace de acesso, considerar uma capacidade média de $512 \mathrm{Kbps}$ por usuário.

- Taxa de entrada de dados por usuário: a taxa total de dados de entrada na praça dividida pelo número de usuários conectados naquele momento.

- RTT: tempo de ida e volta de pacotes até o IP de destino.

- Taxa de perda de pacotes: percentual de pacotes perdidos no caminho de ida ou de volta.

- QoE: visualização do vídeo com as médias dos dados estatísticos de:

- Tempo de espera para carregamento de buffer: tempo despendido para encher o buffer e possibilitar o início da exibição do vídeo.

- Número de congelamentos: número de vezes que o vídeo é interrompido devido a condições inadequadas de rede, para recompor o buffer de recepção.

- Tempo de congelamento: tempo gasto para o vídeo se recuperar de uma interrupção (congelamento da imagem) em uma transmissão.

- Taxa de recepção (vazão): taxa de recepção real, que na teoria deveria ser igual à taxa de codificação do vídeo.

\section{Resultados}

Os resultados são classificados de acordo com as métricas em dois grandes grupos: QoS e QoE. Devido à limitação de espaço são mostrados resultados de apenas duas praças, Praça Conde Francisco Matarazzo na Zona Oeste e Praça Silvio Romero na Zona Leste, com melhor e pior desempenho respectivamente.

\subsection{Qualidade do Serviço (QoS)}

Na Figura 3 é possível observar a taxa de utilização das praças de acordo com dados fornecidos pelas empresas no momento em que ocorreram os experimentos com vídeo. Na Figura 3(a) é possível observar que durante as medições realizadas no domingo a Praça Silvio Romero contava com apenas $10 \%$ do número máximo de usuários, devido ao horário da medição (7:00 horas da manhã), diferente da terça-feira, onde foi observado $40 \%$ do número máximo de usuários porque a medição foi realizada no início da tarde (13:00 horas). Além disso, na sexta-feira não há dados para essa métrica por motivo de falha na captura dos dados. A Figura 3(b) mostra que a praça Francisco Matarazzo apresenta utilização regular também considerando os dias e horários de medição. Para as demais praças ocorre comportamento similar ao da Figura 3. 


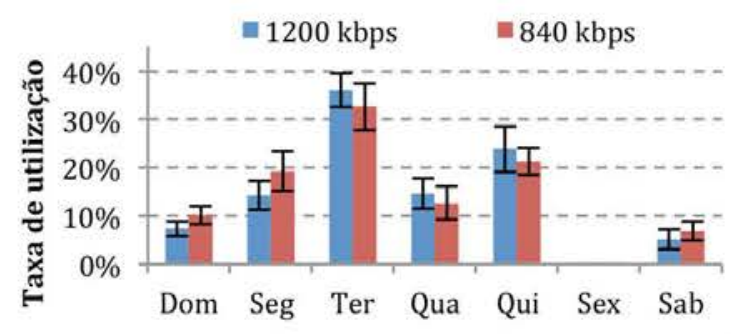

a) Praça Silvio Romero (Leste)

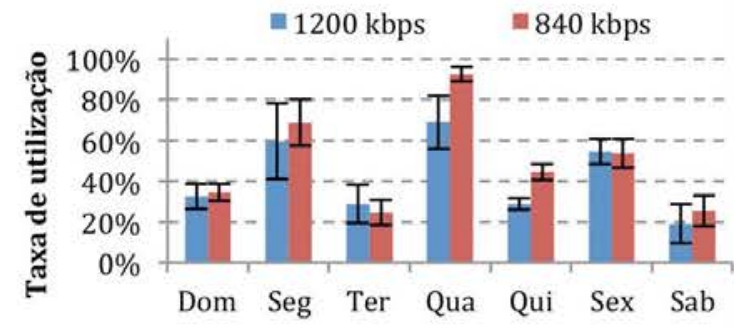

b) Praça Francisco Matarazzo (Oeste)

Figura 3: Nível de utilização das praças

Na Figura 4 é possível observar uma grande diferença entre as duas praças com relação à taxa de transferência de dados (entrada, ou seja download), onde há muito mais dados trafegados na Praça Francisco Matarazzo do que na Praça Silvio Romero. Esse fenômeno ocorre também para as demais praças analisadas, pois cada uma recebe usuários com comportamento e características de uso da rede próprios. A respeito da Figura 4(a) não há dados para a sexta em que foi realizado o experimento de vídeo.

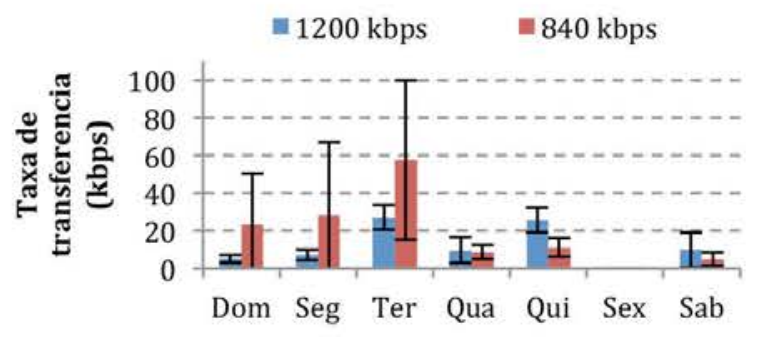

a) Praça Silvio Romero (Leste)

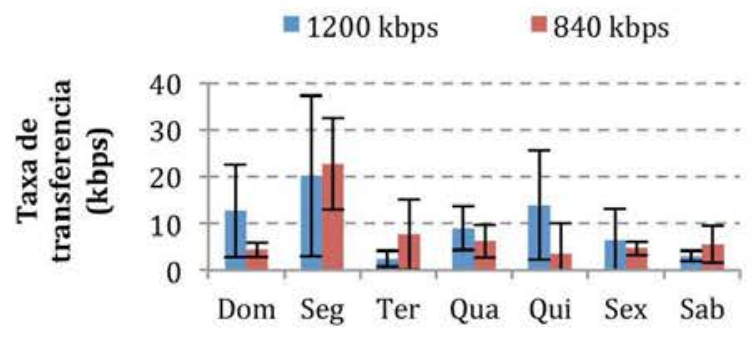

b) Praça Francisco Matarazzo (Oeste)

Figura 4: Taxa de transferência por usuário (download)

Para o atraso em duplo sentido (RTT) é possível verificar na Figura 5(a) que o atraso médio entre os dias da semana sofre alterações muito bruscas, além de grandes variações durante o dia ressaltadas pelo tamanho do intervalo de confiança. Comparando o domingo com a segunda-feira é visível um aumento de quatro vezes. Entretanto, na quarta-feira há uma redução brusca devido ao horário em que foi realizado o experimento. Alguns valores de RTT são claramente inadequados para uma qualidade adequada de utilização da maioria das aplicações na Internet. Esse comportamento ocorre nas praças do Centro e Zona Sul. Já na Praça Francisco Matarazzo na Zona Oeste, Figura 5(b) os valores e a variação são consideravelmente menores, situação similar à Zona Norte.

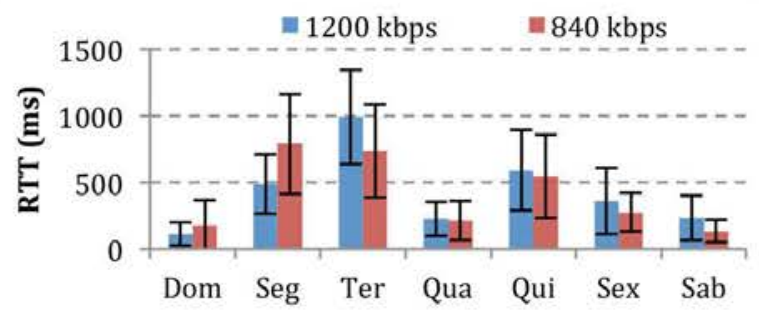

a) Praça Silvio Romero

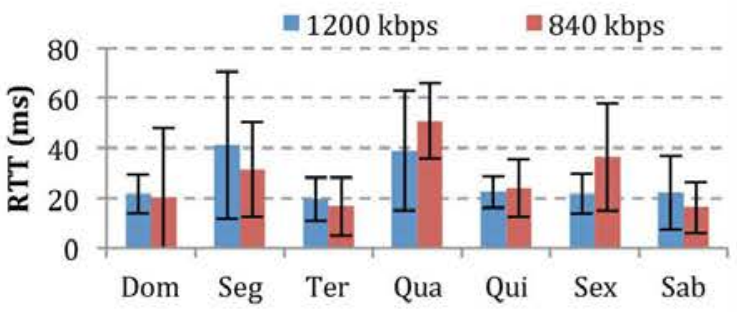

b) Praça Francisco Matarazzo

Figura 5: RTT (atraso em duplo sentido)

Para a perda de pacotes é possível verificar que no melhor caso, Figura 6(b) existe uma perda de no máximo $6 \%$ que ocorre na sexta-feira para o vídeo de maior taxa de 
transmissão. Esse mesmo comportamento foi observado nas praças da Zona Norte e Zona Sul. A Figura 6(a) apresenta um comportamento aceitável para o domingo e a segunda-feira com perda de pacotes na faixa de $1 \%$ a $2 \%$. Entretanto, nos outros dias ocorre uma elevação significativa na perda de pacotes, acima de $20 \%$ na terça-feira e no sábado. Comportamento semelhante a esse ocorre na praça da região central.

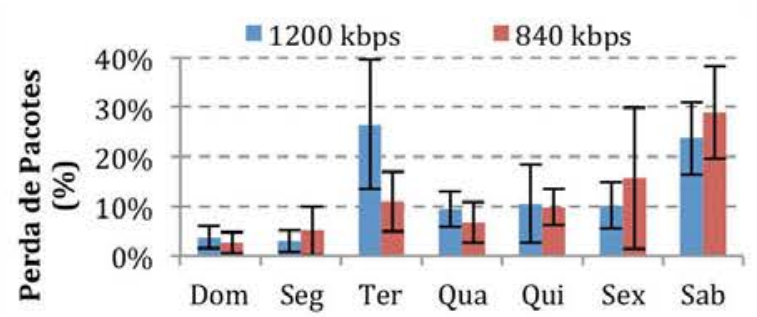

a) Praça Silvio Romero (Leste)

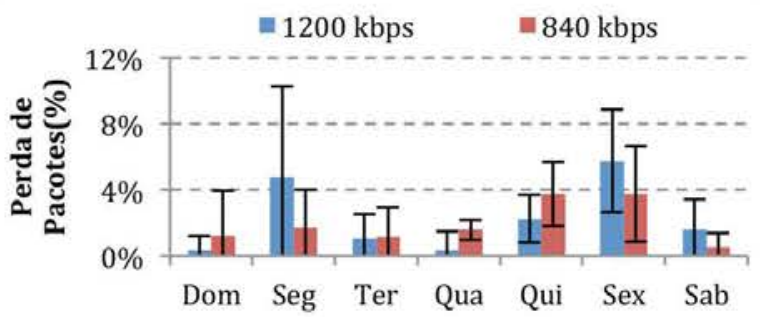

b) Praça Francisco Matarazzo (Oeste)

Figura 6: Perda de Pacotes.

\subsection{Qualidade de Experiência}

Essa seção explora os resultados de QoE, através do tempo de iniciar o vídeo, número e duração dos congelamentos de imagem e taxa de recepção. A Figura 7(a) mostra o tempo necessário para carregar o buffer na Praça Silvio Romero. É possível visualizar que para a maioria dos dias da semana, exceto na segunda-feira, ocorre um atraso significativo para que a exibição do vídeo seja iniciada. Esses dados são corroborados com a baixa taxa por usuário, alta atraso e alta taxa de perda de pacotes evidenciados na seção 4.1. Comportamento semelhante é observável em alguns dias da semana para as praças da zona norte, sul e central. Ao contrário do experimento, que foi executado até o final, para os usuários a percepção negativa de qualidade nessas condições é alta, gerando a desistência de assistir vídeos e impressão negativa da qualidade da praça.

Situação oposta ocorreu na praça Francisco Matarazzo onde o tempo observado para carregar o buffer e iniciar o vídeo permaneceu em torno de dois segundos, Figura 7(b). Mais uma vez, esses dados são corroborados com métricas de QoS mais favoráveis, como uma maior taxa por usuário, menor atraso e menor taxa de perda de pacotes evidenciados na seção 4.1 .

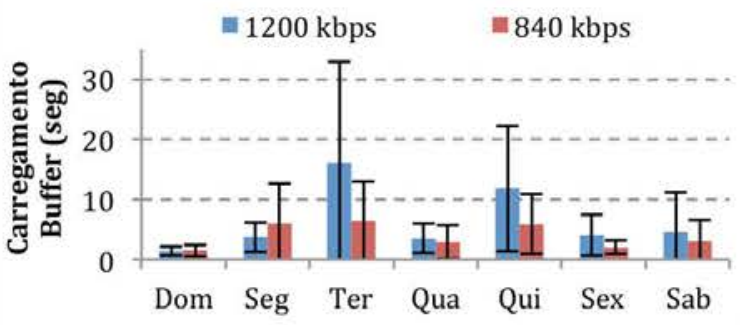

a) Praça Silvio Romero (Leste)

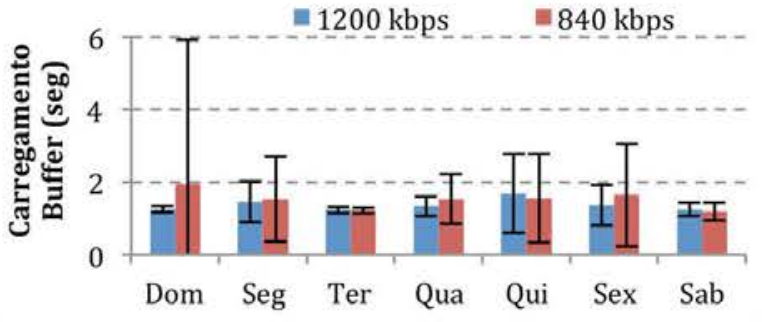

b) Praça Francisco Matarazzo (Oeste)

Figura 7: Carregamento de buffer

Para número de congelamentos do vídeo a Figura 8(a) representa o pior caso observado. Na maioria dos dias da semana é possível visualizar que para o vídeo de qualidade mais alta (1200 Kbps) ocorreram em média quatro congelamentos. Para as cinco praças analisadas a que teve o melhor comportamento foi a praça Francisco Matarazzo, Figura 8(b), onde em média ocorreu um congelamento. Novamente, a percepção de qualidade do usuário decai com as frequente interrupções do vídeo. 


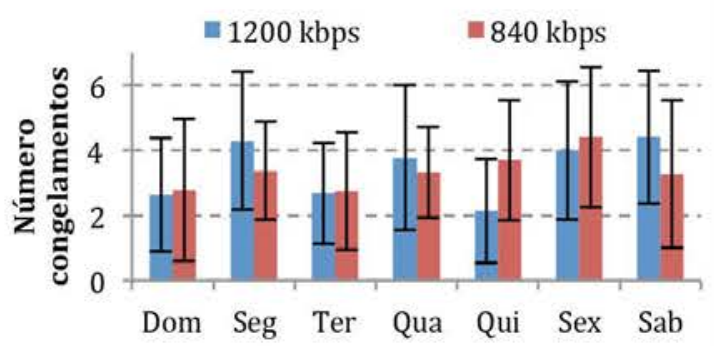

a) Praça Silvio Romero (Leste)

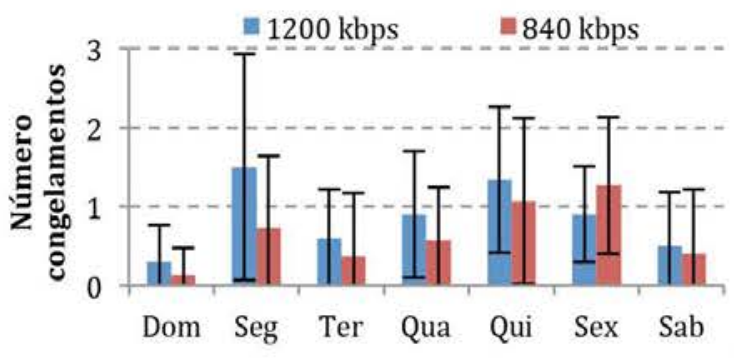

b) Praça Francisco Matarazzo (Oeste)

Figura 8: Número de congelamentos na exibição dos vídeos

Para a duração dos congelamentos, a Figura 9(a) mostra que houve um pico de 30 segundos de congelamento para o vídeo de qualidade alta na terça feira na praça Silvio Romero. É possível visualizar para esse mesmo dia o vídeo de qualidade inferior possui tempo médio de congelamento de aproximadamente 20 segundos. A Figura 9(b) apresenta o melhor caso, com 2 segundos na maioria dos dias. Para as praças do centro e da zona sul ocorre fenômeno parecido com o da Figura 9(a). Já para a praça da zona norte é semelhante a Figura $9 \mathrm{~b}$.

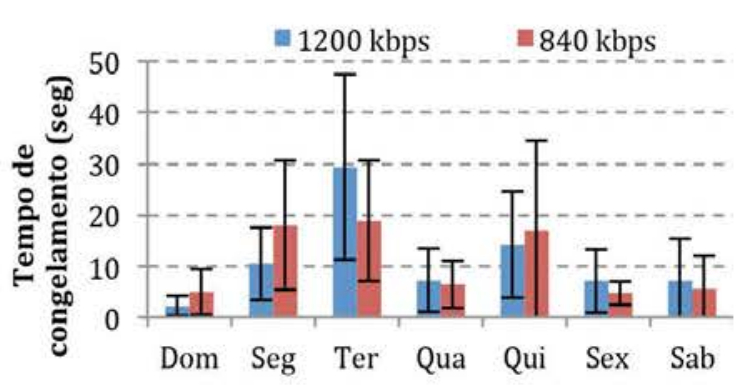

a) Praça Silvio Romero (Leste)

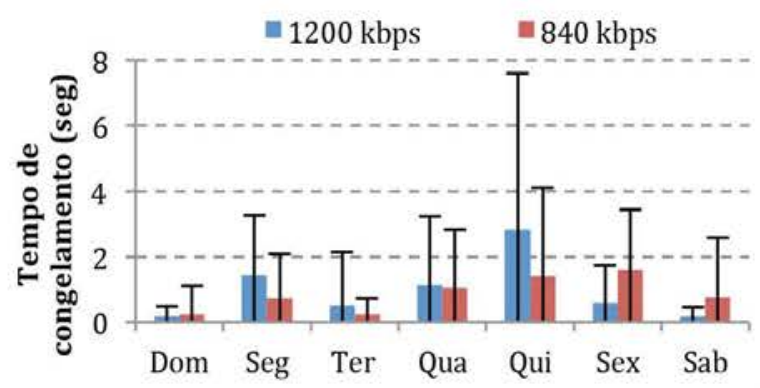

b) Praça Francisco Matarazzo (Oeste)

Figura 9: Tempo médio de congelamento por transmissão de vídeo

As informações sobre a taxa de recepção complementam e corroboram com as anteriores A Figura 10(a) ostra um exemplo em que houve falha na exibição do vídeo, pois há variações significativas na taxa de transmissão. Por exemplo, na terça-feira a taxa deveria estar em $1200 \mathrm{Kbps}$ mas o observado foi algo em torno de $200 \mathrm{Kbps}$, indicando falha grave na execução do vídeo. O caso ótimo é mostrado Figura 10(b) onde para todos os dias as métricas se mantém estáveis em $1200 \mathrm{Kbps}$ para o vídeo de melhor qualidade e $840 \mathrm{Kbps}$ para o vídeo de baixa qualidade.

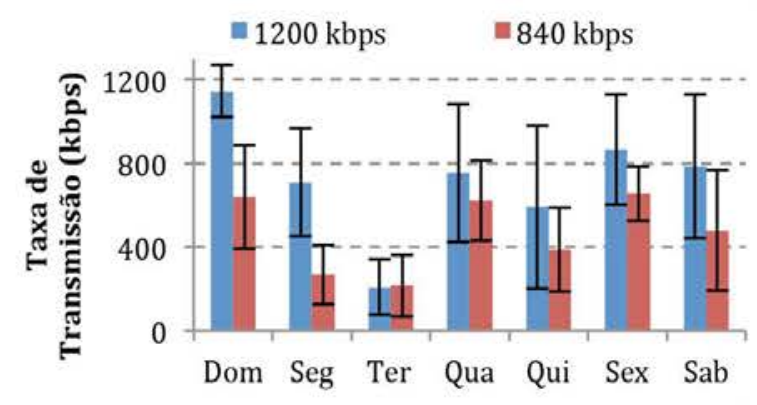

a) Praça Silvio Romero

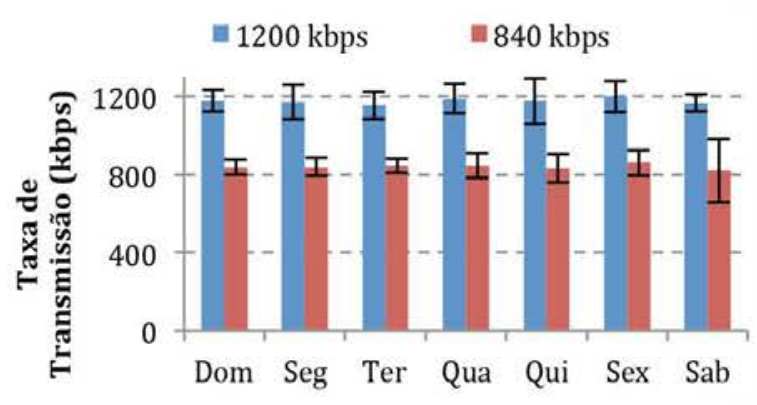

b) Praça Francisco Matarazzo

Figura 10: Taxa de transmissão dos vídeos 


\section{Discussão}

Comparando os resultados de QoS e QoE, é possível observar que existe grande compatibilidade entre eles. Ou seja, quando as condições de rede estão inadequadas, não será possível obter qualidade aceitável na visualização de um vídeo. É importante lembrar que de acordo com as especificações do edital de contratação das empresas prestadoras do serviço da cidade de São Paulo, o taxa média de download para cada usuário deve ser de $512 \mathrm{Kbps}$. Enquanto isso, as duas taxas (e qualidades) de vídeo utilizadas são superiores a esse patamar. Isso significa que para um usuário individual, em algumas praças a qualidade está superior ao que foi contratado, enquanto em outras está significativamente inferior, como pode ser observado na Figura 10(a).

Foi demonstrado também que os resultados das métricas de QoE e QoS se relacionam, que corrobora com a visão intuitiva para essa situação. Por exemplo, o nível de utilização da praça está relacionado com as métricas de taxa de entrada por usuário, atraso e perda de pacotes, que por sua vez influenciam a estabilidade da taxa de recepção do vídeo e os congelamentos de imagem que tanto afetam a percepção de qualidade dos usuários. Além disso, por se tratar de um experimento de medição ativa (gera tráfego) o próprio experimento pode causar a degradação do serviço para os demais usuários da praça.

Para todas as praças foi observado no mínimo um dia em que os experimentos mostram resultados próximos ao caso ótimo, mesmo para a praça Silvio Romero, o que pode ser comprovado com a visualização as figuras (a). No melhor caso da Praça Silvio Romero, a taxa de transmissão chega aproximadamente nos níveis de $1200 \mathrm{Kbps}$ para o vídeo de melhor qualidade e $840 \mathrm{Kbps}$ para o vídeo de baixa qualidade, o que é corroborado pelo duração de congelamento de 5 segundos, ocorrência de congelamento próxima a 2 vezes e carregamento de buffer de 2 segundos, além de perda de pacotes de 4\%, RTT abaixo de $180 \mathrm{~ms}$, baixo nível de utilização, e baixo tráfego de entrada.

Nas cinco praças digitais do programa WiFi Livre SP avaliadas foi identificado um limiar empírico de cerca de $50 \mathrm{~ms}$ de RTT e $3 \%$ de perda de pacotes para garantir uma qualidade de vídeo aceitável para o usuário. Existe uma forte correlação entre esses limiares e a visualização de vídeos nas praças com cerca de dois segundos de carregamento de buffer e apenas um congelamento de aproximadamente no máximo de dois segundos. Isso possibilita que o usuário a assista o vídeo sem muitos interrupções e com qualidade de taxa de transmissão muito próxima ao original transmitido.

\section{Conclusão}

Redes WiFi Municipais tem o objetivo de oferecer ampla conectividade gratuita aos cidadãos, mas já falharam no passado devido a inúmeros problemas técnicos e de regulação. A abordagem desse artigo é a utilização de streaming de vídeo em praças digitais do programa WiFi Livre SP distribuídas pelas cinco regiões da cidade de São Paulo. Foi realizada uma análise de desempenho nas praças utilizando-se de métricas que avaliam tanto a Qualidade de Experiência (QoE) do usuário, como a Qualidade de Serviço (QoS) da rede.

Para todas as praças foi possível verificar que em algum momento no mínimo uma transmissão teve algum tipo de perda, e também de no mínimo uma transmissão sem nenhuma falha. Em média os resultados mostram que para diferentes praças, dias e 
níveis de qualidades de vídeo, na maioria das vezes o resultado é satisfatório para os usuários. Dada a magnitude do projeto, as avaliações até aqui demonstram que a qualidade é variável para praças diferentes.

Como trabalhos futuros, pretende-se efetuar experimentos com vídeo em um número maior de praças, dias e horários, além de utilizar novas métricas de qualidade, assim como identificar um índice de qualidade de vídeo para ambientes de Internet pública via WiFi.

\section{Referências}

Bar, F., Park, N. (2006), "Municipal Wi-Fi Networks: The Goals, Practices, and Policy Implications of the U.S. Case”, Communications \& Strategies, no. 61, p. 107.

Baik, E., Pande, A., Stover, C., Mohapatra, P., (2015), "Video Acuity Assessment in Mobile Devices", IEEE INFOCOM 2015.

Balachandran, A., (2013), "Developing a Predictive Model of Quality of Experience for Internet Video Categories and Subject Descriptors", SIGCOMM, p. 339-350, 2013.

Biswas, S., Backed, J., Wong, E., (2015), "Large-scale Measurements of Wireless Network Behavior", SIGCOMM 2015, p. 153-165, 2015.

Fraser, E., (2010), "A Postmortem Look at Citywide WiFi", Journal of Internet Law, 14(2), August 2010.

Ghosh. A.; et. al. (2011), "Modeling and Characterization of Large-Scale Wi-Fi Traffic in Public Hot-Spots", IEEE INFOCOM 2011.

Juluri, P., Tamarapalli, V., Medhi, D., (2016), "Measurement of Quality of Experience of Video-on-Demand Services: A Survey", IEEE Communications Surveys \& Tutorials, 18(1), First Quarter 2016.

Klaue, J., Rathke, B., Wolisz, A., (2003), "EvalVid - A Framework for Video Transmission and Quality Evaluation", $13^{\text {th }}$ Intl Conference on Modelling Techniques and Tools for Computer Performance Evaluation, pp. 255-272, 2003.

Pinson, M. Wolf, S., (2004), "A New Standardized Method for Objectively Measuring Video Quality", IEEE Transactions on Broadcasting, 50(3), pp. 312-322, September.

Potts, J., "Economics of Public WiFi", Australian Journal of Telecommunications and the Digital Economy, 12(1), Março de 2014.

Ratusznei, J., Silva, W., Pinheiro, N., Melo, R., Kamienski, C. (2015). Uma Rede WiFi Aberta de Larga Escala como Infraestrutura para Cidades Inteligentes, SEMISH 2015.

Serral-Gracia, R., Cerqueira, E., Curado, M., Yannuzzi, M., Monteiro, E., Masip-Bruin, X., (2010), "An Overview of Quality of Experience Measurement Challenges for Video Applications in IP Networks", Intl Conference on Wired/Wireless Internet Communications (WWIC 2010), pp. 252-263.

Sommers, J.; Barford, P. (2012), "Cell vs. WiFi: on the performance of metro area mobile connections”, 2012 ACM conference on Internet Measurement Conference (IMC 2012), p. 301-314.

Wang, Z., Lu, L., Bovik, A., (2002), "Video quality assessment using structural distortion measurement”, International Conference on Image Processing, 2002. 